\title{
STUDI DESKRIPTIF: TEKANAN CUFF ENDOTRACHEAL TUBE (ETT) PADA PASIEN TERINTUBASI DI INTENSIVE CARE UNIT
}

\author{
Setiyawan $^{1}$, S.Dwi Sulisetyawati ${ }^{2}$ \\ 1,2 STIKes Kusuma Husada Surakarta \\ Diterima : 2 Agustus 2018, Disetujui : 16 Agustus 2018 \\ e-mail : etya1025@gmail.com
}

\begin{abstract}
Backgound: Inaccuracy granting ETT cuff pressure can cause a risk of complications that increase the risk of aspiration and trauma to the trachea. Cuff management includes cuff development techniques and intracuff pressure monitoring is a critical component in the treatment of ETT intubated patients in intensive care. The aim of this study was to find out the description of ETT treatment especially on intracuff pressure monitoring. Method: The research methods is a descriptive study in 30 intubated patients in the intensive room of Bagas Waras Klaten Hospital. Result: Based on observations 4 (four) hours after ETT cuff development using cuff inflator, the average results of initial ETT cuff pressure measurements were $28 \mathrm{cmH}_{2} \mathrm{O} \pm 17.43$, then after four hours $19.63 \mathrm{cmH}_{2} \mathrm{O} \pm 17.43$. In conclusion, ETT cuff development using a cuff inflator will tend to decrease intracuff pressure. Conclusion: Periodic monitoring of intracuff pressure is needed to achieve optimal pressure so there are no complications caused by underinflation or overinflation.
\end{abstract}

Keywords: Descriptive Study, ETT Cuff Pressure

\section{PENDAHULUAN}

Gangguan distress pernafasan merupakan masalah utama pada pasien di ruang rawat intensif karena manifestasi klinis distress pernafasan menyebabkan hipoksemia. Kondisi ini memerlukan penanganan segera dengan manejemen hipoksemia yang tepat karena akan berlanjut pada kondisi hipoksia jaringan melalui tindakan manajemen jalan nafas yang cepat. Salah satu tindakan manajemen jalan nafas buatan diruang intensif adalah intubasi endotracheal tube (ETT) untuk menjamin dan mempertahankan patensi jalan nafas, fasilitasi ventilasi dengan tekanan positif pada paru sehingga diharapkan dapat menurunkan kejadian hipoksemia serta dapat mencegah terjadinya inhalasi dan aspirasi saluran cerna.
Endotracheal tube dewasa memiliki sistem fiksasi internal yang disebut dengan cuff (balon udara). Cuff ETT akan masuk ke trachea dan dikembangkan dengan pilot balon. Pengembangan cuff ETT melalui pilot balon menggunakan spuit atau cuff inflator (Stewart, 2013; Sole, 2009). Tekanan cuff ETT harus diukur segera setelah tindakan intubasi dilakukan. Tekanan yang ideal antara 25 $\mathrm{cmH}_{2} \mathrm{O}-30 \mathrm{cmH}_{2} \mathrm{O}$. Tekanan dibawah 20 $\mathrm{cm} \mathrm{H}_{2} \mathrm{O}$ akan menyebabkan risiko aspirasi dan kebocoran oksigen, ventilator associated pneumonia (VAP). Tekanan diatas $30 \quad \mathrm{cmH}_{2} \mathrm{O}$ terjadinya iskemik trakea, obstruksi ETT, kerusakan dinding trakea (Sole et al, 2011). Pengembangan cuff ETT yang kurang akan mengakibatkan kebocoran dan masuknya udara ke lambung atau aspirasi dari cairan 
lambung menuju jalan nafas dan ke paruparu (Sundana, 2008).

Resiko komplikasi akibat tindakan intubasi ETT pada pasien kritis sebesar $54 \%$ dan 28\% terjadi diruang rawat intensif. Hal ini terjadi karena pada pasien kritis mengalami kondisi yang tidak stabil. Perawat memiliki peranan penting dalam melakukan perawatan dan melakukan pengukuran tekanan cuff endotracheal tube terhadap pasien dengan gagal nafas yang terpasang ventilator secara berkala. Pengukuran tekanan cuff endotracheal tube bila tidak dilakukan secara berkala akan memunculkan masalah baru pada pasien yang terpasang ventilator.

Fenomena yang didapat dari hasil studi pendahuluan di Intensive Care Unit (ICU) RSUD Bagas Waras Klaten bahwa pengembangan cuff pada pasien terintubasi ETT menggunakan spuit dengan menginflasikan 5 sampai $10 \mathrm{cc}$ udara ke dalam cuff ETT secara perlahan sampai dirasa cukup. Tekanan intracuff ETT diukur pada pilot balon dengan teknik estimasi jari (finger palpation).

Secara teori metode ini tidak dapat mengetahui tekanan cuff secara tepat sehingga dapat terjadi underinflation atau overinflation. Hal ini dapat mempengaruhi perubahan hemodinamik. Berdasarkan uraian diatas peneliti berminat melakukan tekanan cuff endotracheal tube pada pasien terintubasi.

\section{METODE PENELITIAN}

Penelitian ini merupakan studi deskriptif analitik pada 30 responden terintubasi dan terpasang ventilasi mekanik di ruang ICU RSUD Bagas Waras Klaten pada bulan Maret sampai Juni 2018. Pengumpulan data primer dilakukan dengan mengamati teknik pengembangan cuff ETT pada pasien terintubasi, jumlah volume udara yang diinflasikan dicatat dan diukur, kemudian tekanan cuff dinflasikan dengan cuff inflator sesuai standar normal sebesar 25 $\mathrm{cmH}_{2} \mathrm{O}$. Setelah 4 jam dari pengembangan cuff $25 \mathrm{cmH}_{2} \mathrm{O}$, dilakukan pemantuan tekanan intracuff menggunakan untuk mengetahui perubahannya. Data sekunder dikumpulkan dari rekam medik untuk mengetahui karakteristik responden. Selanjutnya data yang terkumpul digambaran dalam bentuk distribusi frekuensi.

\section{HASIL PENELITIAN}

Mendiskriptifkan karakteristik masing-masing variabel yang diteliti berdasarkan jenis kelamin, umur, dan penyakit pasien, ukuran ETT dan tekanan cuff ETT yang ditampilkan dalam distribusi tabel berikut:

Tabel 1. Distribusi responden berdasarkan jenis kelamin dan penyakit pasien terintubasi

\begin{tabular}{lcc}
\hline Variabel & Jumlah & Persentase \\
\hline Jenis Kelamin & & \\
Laki-laki & 15 & 50 \\
Perempuan & 15 & 50 \\
Jenis Penyakit & & \\
Bedah & 19 & 63.3 \\
Non Bedah & 11 & 37.7 \\
\hline
\end{tabular}

Distribusi jenis kelamin responden merata antara laki-laki dan perempuan yaitu 15 orang (50\%). Sedangkan distribusi jenis penyakit paling banyak adalah penyakit bedah 19 orang $(63.3 \%)$ dan non bedah sebanyak 11 orang $(37,7 \%)$. 
Tabel 2. Distribusi responden berdasarkan umur dan ukuran ETT pada pasien terintubasi

\begin{tabular}{lllll}
\hline Variabel & Mean & SD & $\begin{array}{l}\text { Min- } \\
\text { Maks }\end{array}$ & $\begin{array}{l}\mathbf{9 5 \%} \\
\text { CI }\end{array}$ \\
\hline Umur & 32,46 & 11,63 & $18-50$ & $\begin{array}{l}29,4- \\
\end{array}$ \\
Ukuran & 7,26 & 0,32 & $7-8$ & $\begin{array}{l}36,86 \\
7,15-\end{array}$ \\
ETT & & & & 7,35 \\
\hline
\end{tabular}

Hasil analisis didapatkan rata-rata umur responden adalah 32,46 tahun, umur termuda adalah 18 tahun dan umur tertua adalah 50 tahun. Karakteristik responden berdasarkan ukuran ETT didapatkan hasil analisis bahwa rata-rata ukuran diameter ETT responden adalah 7,26 $\mathrm{mm}$. Ukuran diameter yang paling kecil adalah $7 \mathrm{~mm}$ sedangkan ukuran diameter ETT yang paling besar adalah $8 \mathrm{~mm}$.

Tabel 3. Distribusi responden berdasarkan ukuran tekanan cuff ETT pasien terintubasi

\begin{tabular}{lcccc}
\hline \multicolumn{1}{c}{ Variabel } & Mean & SD & $\begin{array}{c}\text { Min- } \\
\text { Maks }\end{array}$ & 95\% CI \\
\hline $\begin{array}{l}\text { Tekanan cuff } \\
\text { awal }\end{array}$ & 28,00 & 17,43 & $4-70$ & $\begin{array}{c}22,27- \\
33,73\end{array}$ \\
$\begin{array}{l}\text { Tekanan cuff } \\
25 \text { cmH }_{2} \mathrm{O}\end{array}$ & - & - & - & - \\
$\begin{array}{l}\text { Tekanan cuff } \\
\text { setelah empat } \\
\text { jam }\end{array}$ & 19,63 & 9,84 & $5-58$ & $16,40-$ \\
\end{tabular}

Berdasarkan tabel 3 dapat diketahui bahwa pada pengukuran awal tekanan cuff ETT sebesar $28 \mathrm{cmH}_{2} \mathrm{O}$, kemudian menjadi $19.63 \mathrm{cmH}_{2} \mathrm{O}$ setelah empat jam diberikan tekanan cuff 25 $\mathrm{cmH}_{2} \mathrm{O}$.

\section{PEMBAHASAN}

Kebanyakan tipe ETT yang digunakan pada responden adalah high volume low pressure (HVLP) dengan brand march yang bervariasi. Pengembangan cuff ETT dilakukan menggunakan spuit dengan metode finger palpation. Pada metode ini pengembangan cuff ETT dilakukan dengan menginflasikan 5 sampai $10 \mathrm{cc}$ udara ke dalam cuff ETT. Tekanan cuff diukur melalui pilot balon dengan cara palpasi. Jika dirasa cukup maka pengembangan dihentikan. Metode ini sangat berbahaya karena tidak dapat mengetahui tekanan cuff yang tepat sehingga dapat terjadi underinflation atau bahkan overinflation.

Analisis univariabel seperti pada tabel 3, menunjukkan rata-rata tekanan cuff ETT pada pengukuran awal adalah 28 $\mathrm{cmH}_{2} \mathrm{O}$ kemudian menjadi $19.63 \mathrm{cmH}_{2} \mathrm{O}$ setelah empat jam pemberian tekanan cuff $25 \mathrm{cmH}_{2} \mathrm{O}$. Memperhatikan angka-angka tekanan cuff ETT tampak memiliki kecenderungan yang semakin lama semakin menurun. Secara klinis pada penelitian ini menyatakan bahwa tekanan cuff akan mengalami perubahan setelah 4 jam. Hasil penelitian ini sejalan dengan penelitian yang telah dilakukan oleh Sridermma, et. al., (2007) yang menyatakan bahwa volume udara cuff ETT dapat mengalami perubahan dalam waktu 4-5 jam.

Tekanan cuff ETT bisa mengalami peningkatan dan penurunan. Adapun faktor yang menyebabkan penurunan tekanan cuff ETT adalah aktifitas yang menyebabkan pergerakan ETT ke arah dalam, suction mulut, suction ETT, oral higyne, pasien berusaha berbicara, kebocoran cuff ETT, terjadinya ekstensi pada leher serta perubahan posisi (Morgan et. al., 2012).

Menurut penelitian Chendraskhar \& Timberlake, (2010) menyatakan bahwa tekanan minimum occlusive intracuff yang dibutuhkan untuk mencegah aspirasi pada ventilasi positif adalah sebesar 27 $\mathrm{cmH} 2 \mathrm{O}$, dan aspirasi terjadi jika tekanan intracuff dibawah $20 \mathrm{mmH} 2 \mathrm{O}$. Hal ini 
dapat dipengaruhi oleh jenis bahan ETT dan volume yang diisikan ke dalam cuff, diameter trakea, jenis dan ukuran ETT serta perubahan tekanan rongga toraks (Sole et al, 2009). Tekanan cuff ETT yang direkomendasikan adalah antara 25-30 $\mathrm{cmH}_{2} \mathrm{O}$ untuk pemeliharaan (Sole et al, 2009; Spiegel, 2010).

\section{KESIMPULAN DAN SARAN}

Berdasarkan penelitian terdapat kecenderungan penurunan tekanan cuff ETT setelah 4-5 jam dan berdasarkan kajian literatur yang ada bahwa pengembangan cuff pada rentang ideal sangat penting untuk meminimalkan komplikasi. Selain itu, pengembangan cuff ETT menggunakan spuit dengan metode finger palpation yang selama ini dilakukan tidak dapat mengetahui dengan tepat jumlah volume udara yang dibutuhkan untuk mencapai tekanan intracuff ideal yaitu $25 \mathrm{cmH} 2 \mathrm{O}-30$ cmH2O. Hal ini dapat menyebabkan terjadinya underinflation atau bahkan overinflation yang akan berdampak pada perubahan hemodinamik pasien. Hendaknya dilakukan pengontrolan tekanan cuff endotracheal tube secara periodek terutama saat ada aktifitas dan tindakan perawatan pada pasien yang terkait dengan perawatan ETT agar tekanan cuff endotracheal tube terjaga dalam batas tekanan normal

\section{DAFTAR RUJUKAN}

Chendraskhar A., Timberlake, G. (2010). Endotracheal Tube Cuff Pressure Treshold For Prevention of Nasocomial Pneumonia. The Journal Of Applied Research In
Clinical And Experimental Therapeutics.

Morgan G.E., Mikhail M.S., Murray M.J., Larson C.P. (2012). Clinical Ansthesiology. $5^{\text {rd }}$ ed. New York.: Lange Medical Book

Sole M.L., Penoyer D.A., Su X.G., Jimanez., Kalita S.J., Paolilo E., Byers J.F., Bennett M., Lucky J.F (2009). Assesment Endotracheal Cuff Pressure by Continous Monitoring : a Pilot Study. American Journal of Critical Care Volume 18. No. 2.

Sole M.L., Su X., Telbert S., Penoyer D.A., Kalita S., Jimanez E., Ludy J E., Bennett M. (2011). Evaluation of an Intervention to Maintain Endotracheal Tube Cuff withiin Therapeutic Range. American Jurnal of Critical Care 20, 109118

Spiegel, J. E. (2010). Endotracheal Tube Ciff. Journal. 51-52.

Sridermma, S., Lintangturakool, S., Wongsurakiat, P., Thamlikitkul, V. (2007). Development of Appropriate Procedure for Inflation of Endotracheal Tube Cuff in Intubation Patients. $J$ Med Assoc Tahi vol 90 Suppl. 2

Stewart, S.L., Secrest, J.A., Norwood., Zachary, R. (2013). A Comparison of Endotracheal Tube Cuff Pressure Using Estimation Technique and Direct Intracuff Measurement. AANA Journal/Desember/Vol 71 .No.6

Sundana K, (2008). Ventilator Pendekatan Ptaktis di Unit Perawatan Kritis Edisi 1 Volume 1 : Bandung. CICU RSHS 